\title{
Actor teaches clinicians to communicate
}

Many patients have horror stories about their doctor's hurried standoffishness and seeming indifference. Actor Megan Cole learned this first hand while starring as Vivian Bearing, a professor dying of cancer, in the Pulitzer Prize winning play Wit. Cole encouraged the audience to talk about their own experiences and recognized a gap between how patients and physicians experience the doctor-patient relationship. She also realized that, as an actor, there was something she could do to help.

Working with the US-based Compassion in Dying Federation, Cole developed a program in medical ethics and communication. Her course, "The Craft of Empathy," shows doctors how to use actors' techniques to heighten $\infty$ their awareness of emotions such as anger, fear and sadness and respond to them without losing professional objectivity.

Barbara Coombs Lee, president of the federation, says many doctors lack rapport with their patients. "We speak with dying patients and their families all of the time and we have observed a pattern in many of the complaints. Patients have a sense that their doctors are not really hearing them."

Coombs Lee says the heavy science requirements of medicine leave many physicians without an education in humanities, which is the basis for empathy. In addition, physicians who are naturally inclined to be empathetic "have it trained out of them."

Cole, who has appeared on Seinfeld and $E R$, is now a regular visiting faculty member at the University of Texas Medical Center in Houston and part of what she calls a tiny movement honouring the human aspect of medicine.

Among the 40 or so people behind this so-called communications movement is Dr. Robert Buckman, an oncologist at the Princess Margaret Hospital. He says contrary to stereotypes about doctors being anti-soft skills, these efforts have been well received. "Many doctors express

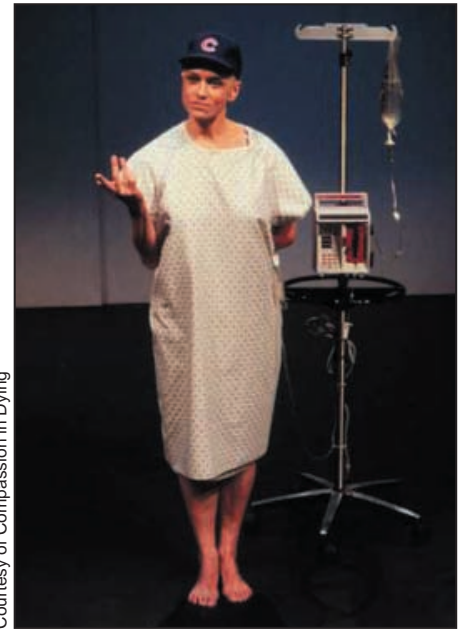

Actor Megan Cole learned about the gap in patient-physician communications from her role in Wit.

relief that others feel this way too." Buckman says that physicians have not been taught how to express themselves and so they often appear heartless. "The emotions are there, they just don't come across, and actors are in a perfect position to help physicians develop these skills." Allison Gandey, CMAJ

\section{Women's Health}

\section{UK approves informed C-sections on demand}

The UK has entered the debate about women's right to choose how they give birth ( $C M A \mathcal{F}$ 2004;170[5]:813-4) with the publication of new clinical guidelines for cesarean sections by the National Institute of Clinical Excellence (NICE) (http://www.nice.org.uk).

The guidelines for the $\mathrm{Na}$ tional Health Services in England and Wales provoked a flurry of media reports claiming that the institute had decided $\infty$ that cesareans must be discouraged. BBC Online and others stated that NICE wanted doctors to try to persuade women not to elect for cesareans.

But one of the guidelines authors says these reports are wrong: the new recommenda- tions do not restrict choice. Obstetrician David James said: "The fact is that there are benefits and disadvantages to both vaginal and cesarean delivery. Both methods never leave the woman unscathed. What the guidelines say is that it is irresponsible to do a cesarean on request without exploring with the woman why she made that choice and [ensuring] that she understands the pros and cons and risks."

The guidelines say that individual clinicians have the right to decline a request for a cesarean in the absence of an identifiable reason, but the woman has a right to a further referral.

"Undoubtedly, we'd do a cesarean for someone if we've gone through these steps," added
James, a professor at the Queen's Medical Centre in Nottingham.

While critics say the guidelines overstate the risks of cesarean delivery, James said the vast majority of obstetricians and gynecologists agree with the new recommendations.

Consultant obstetrician and fetal medicine specialist Chris Griffin said most of his colleagues back NICE. However, he said more fundamental problems in NHS maternity services - such as understaffing should be addressed first.

Like Canada, about 1 in 5 births in England and Wales is by cesarean. In the UK, $7 \%$ of cesarean births were elective. - Colin Meek, Wester Ross, Scotland 